\title{
Bilateral cytomegalovirus retinitis with coats-like presentation in an HIV patient
}

\section{Retinitis por citomegalovirus bilateral con reacción tipo Coats en paciente portador del VIH}

\section{P. Ayumi Kawakami-Campos*}

Secretaria de Salud, Mexico City, Mexico

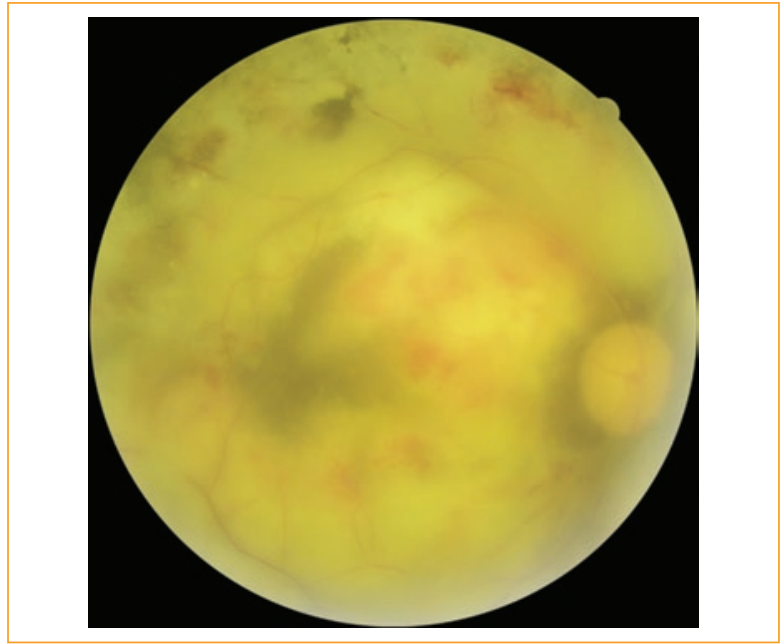

Figure 1. Clinical image of the right fundus with poor visualization due to dense vitritis. Multiple hemorrhages associated with extensive retinitis, vascular sheathing, coalescent hard subretinal exudates, and optic disc pallor.

This is a 43-year-old male patient, assessed at the Condesa Iztapalapa Specialized Clinic due to a history of unintentional weight loss $(10 \mathrm{~kg})$ in 3 months. He refers to multiple episodes of gastroenteritis with a torpid evolution despite treatment and poor bilateral visual

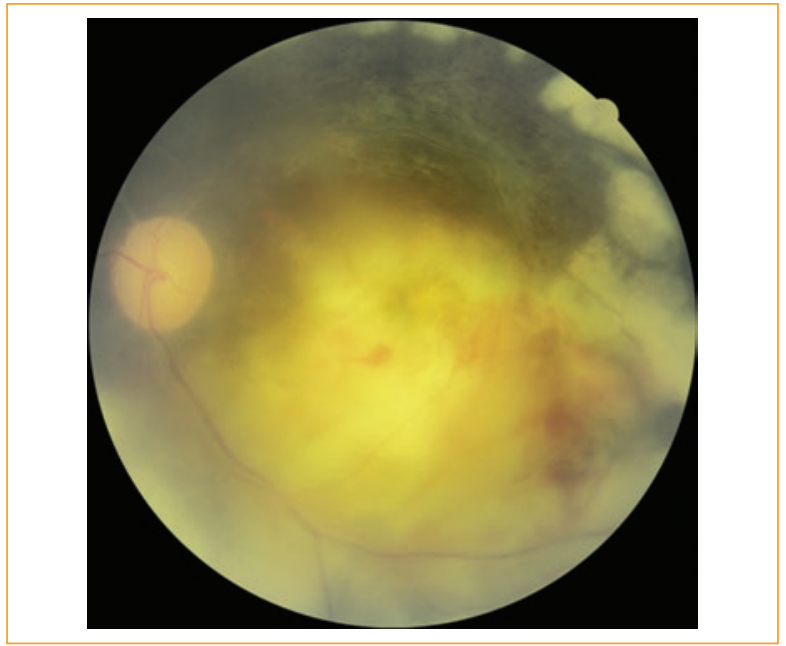

Figure 2. Clinical image of the left eye fundus with poor visualization due to dense vitritis. Cytomegalovirus retinitis with associated retinal hemorrhages, generalized vascular sheathing, optic nerve pallor, and regions of retinal atrophy with secondary fibrosis in the upper retina.

acuity for the past 4 months. At the time of diagnosis, he had a CD4 T-lymphocyte count of 19 cells $/ \mathrm{mm}^{3}$ with $3 \%$ and a HIV viral load of 1,469,855 copies $/ \mathrm{ml}$.

Ocular examination revealed a visual acuity of no light perception in both eyes, anterior segment with

\section{Correspondence:}

${ }^{*}$ P. Ayumi Kawakami-Campos

Combate de Celaya, s/n

Date of reception: 29-07-2018 C.P. 09730, Mexico City, Mexico E-mail: ayumika@gmail.com 2604-1731/@ 2018 Sociedad Mexicana de Oftalmología. Published by Permanyer México SA de CV. This is an Open Access article under the CC BY-NC-ND license (http://creativecommons.org/licenses/by-nc-nd/4.0/).
Available online: 01-09-2019 Rev Mex Oftalmol (Eng). 2019;93(5):40-41

www.rmo.com.mx 


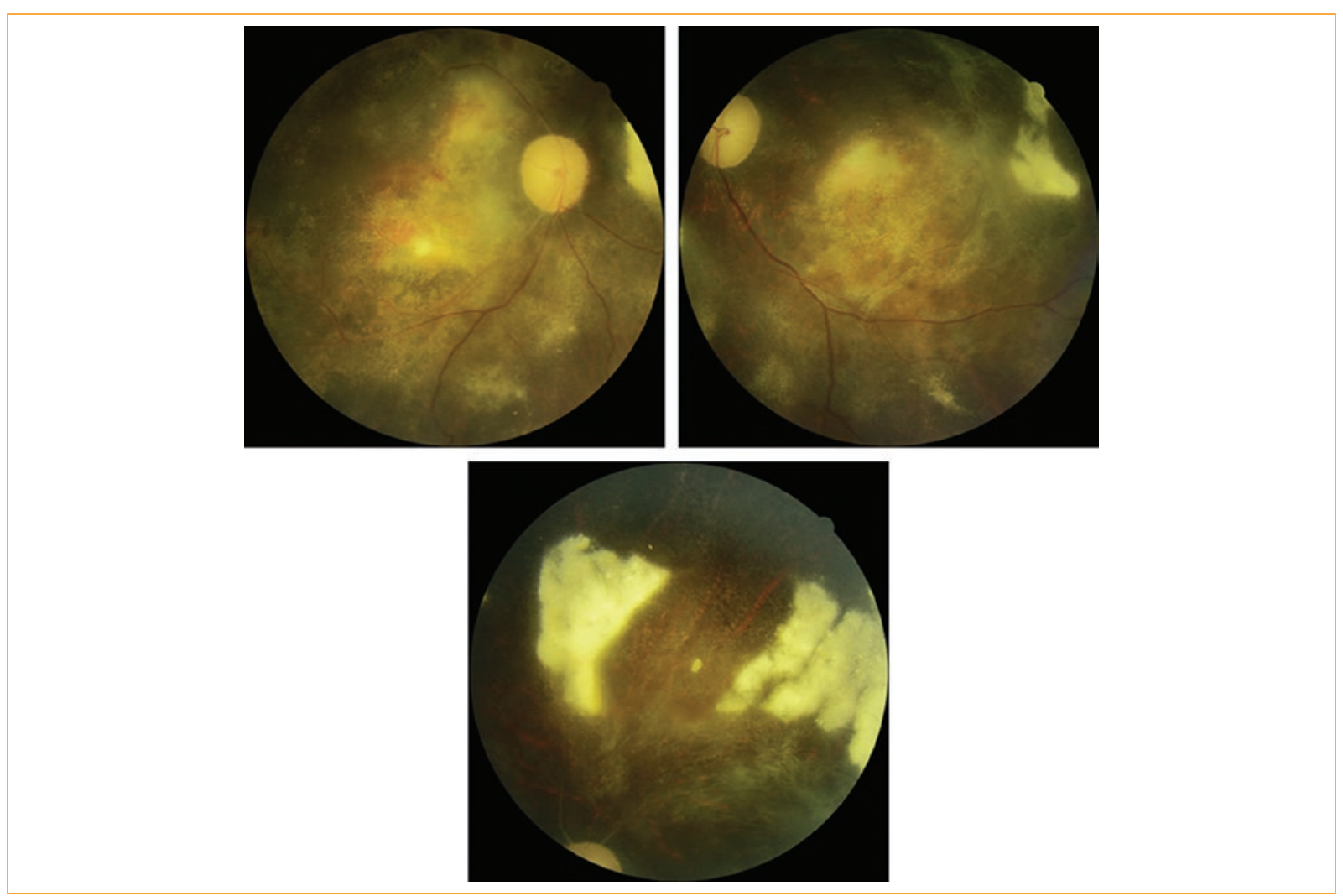

Figure 3. Clinical photographs of the posterior pole of both eyes and the right peripapillary region; photographic control after 1 month of treatment. The resolution of the exudative reaction reveals extensive retinal atrophy with visualization of the retinal pigment epithelium, residual vascular hyalinization, optic disc atrophy, and patches of subretinal fibrosis.

normal anatomy, bilateral afferent pupillary defect, significant vitritis, extensive cytomegalovirus retinitis covering from zone 1 to 3 in all quadrants, associated with iridescent subretinal exudates with a coats'-like pattern, optic disc pallor, extensive vascular hyalinization, and vascular sheathing on both eyes (Figs. 1 and 2). This presentation with extensive subretinal exudation is considered atypical regarding the three patterns described in this disorder: granular, brushfire, and frosted branch. Due to equipment unavailability, it was not possible to perform fluorescein angiography or optical coherence tomography.

Treatment was started with valganciclovir $900 \mathrm{mg}$ every $12 \mathrm{~h}$ orally, and 5 days later, the patient started antiretrovirals with emtricitabine $200 \mathrm{mg} /$ efavirenz $600 \mathrm{mg} /$ tenofovir disoproxil $300 \mathrm{mg}$ every $24 \mathrm{~h}$. Gradual treatment initiation aims to reduce the risk of immune reconstitution inflammatory syndrome.

Despite having a visual acuity of no light perception, the treatment for cytomegalovirus retinitis is considered justified since it is the manifestation of systemic viral infection with the potential to endanger the patient's life.
One month later, the afferent pupillary defect persisted, and the visual acuity remained in no light perception in both eyes. Cytomegalovirus retinitis is in remission, with partial reabsorption of the subretinal hard exudates, extensive optic and retinal atrophy with visualization of the retinal pigment epithelium (Fig. 3).

The patient stopped attending the health services of Mexico City a few weeks after the last ophthalmological examination.

\section{Ethical disclosures}

Protection of human and animal subjects. The authors declare that no experiments were performed on humans or animals for this study.

Confidentiality of data. The authors declare that they have followed the protocols of their work center on the publication of patient data.

Right to privacy and informed consent. The authors have obtained the written informed consent of the patients or subjects mentioned in the article. The corresponding author is in possession of this document. 